\title{
How to be critical and realist about economics
}

\section{Ylikoski, Petri K}

Routledge

2012

Ylikoski, P K \& Kuorikoski , J 2012 , How to be critical and realist about economics . in A Lehtinen, J Kuorikoski \& P Ylikoski (eds), Economics for real : Uskali Mäki and the place of truth in economics. Routledge INEM Advances in Economic Methodology, vol. 14 , Routledge, London, pp. 255-273 .

http://hdl.handle.net/10138/233979

acceptedVersion

Downloaded from Helda, University of Helsinki institutional repository.

This is an electronic reprint of the original article.

This reprint may differ from the original in pagination and typographic detail.

Please cite the original version. 
Published in Jaakko Kuorikoski, in Kuorikoski, Lehtinen \& Ylikoski (eds.):

Economics for Real: Uskali Mäki and the Place of Truth in Economics,

Routledge, 255-273.

\section{Jaakko Kuorikoski \& Petri Ylikoski}

\section{How to Be Critical and Realist about Economics ${ }^{i}$}

\section{INTRODUCTION}

Scientific realists take science seriously. First, they take the epistemic aims of science seriously. For realists, the main epistemic goal of science is understanding the world and how it works. While instrumentalists put the emphasis on prediction and practical applicability, realists think that this is not enough. Science should also aim to explain things. Second, realists take science seriously by setting high standards for the ultimate evaluation of scientific claims. While social constructivists and other non-realists might be satisfied with the consensus of the relevant community, realists think that scientists should be more ambitious: they should attempt to get things right. For realists, most scientific claims are about things that exist independently of the epistemic activities of scientists. According to realists, scientific statements are truth-apt: it makes sense to talk about their truth and falsity even if the entities mentioned in such statements are about the unobservable. The third indication of realists taking science seriously is the emphasis they put on the critical evaluation of current epistemic practices. The explanatory goals of science and the non-epistemic notion of truth give realists the 
standard according to which our methodological ideas should be evaluated. For a realist, it is entirely possible that the principles of evidential and explanatory reasoning employed within a scientific field are inappropriate for the goals of science.

The above characterization provides the general spirit of scientific realism. When realists begin to articulate the details of their position, a lot of variation is possible. Consequently, scientific realism is not a monolithic doctrine. There are a number of different ways to be a scientific realist. Given this background, it is surprising that in the social sciences, one specific formulation of realism dominates the discursive landscape. This approach is called critical realism. While there are some differences between different advocates of critical realism, its central ideas and arguments derive from the early work of Roy Bhaskar (1975; 1979), who in turn was inspired by the work of Rom Harré $(1970 ; 1975)$. In economics the main advocate of critical realism has been Tony Lawson (1997; 2003). Although critical realism in economics is certainly a broader movement with some internal doctrinal variation, we limit our discussion to its most important representative.

In this paper we argue that, despite its influence, critical realism is not the most promising version of scientific realism for economics. The main problem with 
critical realism is its hermetic insulation from the mainstream of the philosophy of science. We argue that this intellectual isolation is unfortunate, as it has meant that critical realism has missed many opportunities to develop its central concepts, such as causal mechanism, emergence, and explanation. At the same time, we argue, critical realists have missed some crucial aspects of the intellectual strategy of modern economics. Our point is not to defend mainstream economics, rather it is to show that a better understanding of modeling as a scientific research strategy opens up the possibility of a more penetrating analysis of its possible shortcomings.

Critical realism certainly shares many central tenets with Mäki’s realist vision of economics, such as the emphasis on observer-independent truth and the importance of finding causal mechanisms. Yet there is a crucial difference. Uskali Mäki's philosophical project has been the formulation of a form of realism which renders economic modeling at least potentially compatible with scientific realism, despite the ubiquitous idealizations and outright fictions. The introduction of falsities is necessary in isolating significant truths from the complexity of economic systems in a tractable way. Whether the resulting models actually manage to isolate the most important economic mechanisms in a way which would result in improved understanding and better tools for intervening in the economic reality, cannot be decided by purely philosophical argumentation. In contrast, the critical realist is unwilling to vindicate radical idealizations in 
economics in this way. For the critical realist, the complexity of social life cannot be decomposed into manageable parts with theoretical isolations, and some other way of making sense of economic phenomena must therefore be found.

But what do the critical realists have to offer as an alternative for the model-based strategy of mainstream economics? In our assessment, this is the most damning failure of critical realism as a philosophy of science: it offers very little in the form of positive ideas and "realistic" tools with which to correct our social science practices. In this paper, we will focus on the central positive critical realist proposal for a more fruitful economic methodology: contrastive explanation. We acknowledge that there are other methodological proposals, such as "iconic modeling" (Harré 2004: ch. 1), but we will leave these out of our discussion in order to reserve space for a thorough discussion of what we take to be the most important positive methodological suggestion, especially in the context of economics. We make our case by examining a recent paper by Lawson (2009a). In this paper, Lawson applies the conceptual apparatus of critical realism in general, and the idea of contrastive explanation in particular, to analyze a prominent example of economic reasoning: Akerlof's celebrated paper on informational asymmetries, “The Market for'Lemons" (1970). We argue that a better analysis of the case can be made by employing ideas developed recently in philosophy of science. By combining some recent ideas about contrastive explanation with Uskali Mäki's insights about the method of isolation, it is possible to obtain a better realist platform for a critical engagement with the economics. 


\section{THE KEY IDEAS OF CRITICAL REALISM}

The critical part of critical realism stems from the conviction that epistemic practices should be evaluated according to whether or not they suit the nature of the phenomena that they are used to study. Epistemology should follow ontology. (Lawson 2003: 12) The central critical realist argument against mainstream economics can be summarized as follows. Mathematical economic model building is an explanatorily infertile exercise because it presupposes a "deductivist" model of explanation, according to which explanation amounts to the subsumption of individual events under occurrent event regularities (constant conjunctions and correlations between observed phenomena). The existence of such event regularities requires that the system is closed, that is, that the causal powers of the entities composing the system act "atomistically," and that the system itself is suitably shielded from outside disturbances. However, social systems in general and economic systems in particular are neither atomistic nor closed, hence the model-based mainstream project is doomed to failure. (Lawson 1997; 2003.)

Lawson has recently emphasized that the problem with economics is not positivism or generally Humean metaphysics as such. He now acknowledges that even mainstream economists are not in fact looking for regularities in the data, but 
rather for the causal mechanisms underlying the observed regularities and patterns (stylized facts, correlations between variables, etc.) (2003: 25; 2009b). This point has been driven home by Wade Hands, Kevin Hoover, and Jack Vromen, among others (Hands 1997; Hoover 2002; Vromen 2009). Even though economists seem to derive descriptions of regularities from the standard axioms of rational choice, these axioms describe the components of economic causal mechanisms. But what Lawson insists upon is that the "deductivist" explanatory methodology of model building is nevertheless ill suited for the purpose of describing causal mechanisms in the social realm. The argument is that every deduction within a model presupposes the truth of a claim about a strict event regularity: whenever the premises are true, then the conclusion will also be true. And this won't work, because the social realm is neither atomistic nor closed (Lawson 2009b).

A closed system is a set of entities and causal powers that is shielded from outside disturbances (extrinsic closure) and one that does not exhibit complex endogenous dynamics and novel behavior (intrinsic closure). As Nancy Cartwright (1997) has put it, such a closed system is a nomological machine which produces observed regularities. However, lawlike regularities are hard to come by in the wild, because their production is anything but a trivial matter. In the physical sciences, such closures can be achieved in the laboratory and this closure is epistemically useful because we can learn about the (unobserved) mechanisms and powers by intervening experimentally on parts of the system and then observing how the 
observed regularities change. Closure and experimental control enable us to formulate "deductive" explanations: $y$ is explained by pointing out that $x$ and, ceteris paribus, whenever condition $x$, then consequence $y$ invariably follows.

The social realm is closed only in the most uncommon of situations. All social and economic systems are nested within and in constant contact with other social and economic systems. Moreover, the social world is reproduced and transformed by human agency, which provides the social world with unpredictable endogenous dynamics. Real economic agents are purposive and innovative, constantly exhibiting novel and unpredictable behavior. Lawson takes this fundamental fact to be the essence of the Lucas critique, and that it thus shows the a priori futility of all "deductivist" modeling, not just the project of structural macroeconometrics (Lawson 1997: 81-83). Spatially and temporally fleeting closures can occur when the social situation is highly isolated, stabilized by powerful external causes, and in which the viable alternative courses of actions of the agents are reduced to one. For example, the behavior of single agents in a traffic jam is relatively predictable, because the action of the agent is so highly constrained. Yet these situations are the extreme exception rather than the norm. Instances of such temporary and incomplete closures may give rise to observable "demi-regularities", which can constitute important evidence for causal inquiry and legitimate targets for statistical techniques, but cannot as such salvage the feasibility of deductivist explanation (Lawson 1997: ch. 15). 
A system is composed of atomistic causal powers if the causal powers are intrinsic properties of the components and if the interaction of the powers is separable (additive). The separability of powers eases the formulation of deductive explanation because the causal web can be decomposed into separate causal laws, according to which, whenever factor $x$ is present, its causal contribution is $y$ (Lawson 2003: 13-16). According to critical realists, the social realm is not atomistic, because the causal powers are relational or made up of "internal relations" and the consequences of their interaction are emergent. The fact that the social realm is constituted by internal relations is established by transcendental deduction: the existence of the social status of a student is a conceptually necessary condition for someone to be a teacher and the causal powers of the teacher derive from this internal relationship. These causal powers are not separable, because the internality of the causal relations and the creative aspect of human agency mean that the joint causal consequences of these powers are always emergent (ibid. 39-44). The social realm is something over and above the sum of its parts and, hence, it cannot be reduced to, or even investigated as, separable causal regularities. 
Where then, lies the hope for the economist? Remember that the mainstream economist and the critical realist share the same goal of finding out the causal mechanisms behind economic phenomena. For the remainder of the paper, we will explore what critical realism has to offer to replace the mainstream "deductivist" method of explanation. We will focus on Lawson's proposals concerning contrastive explanation $(2003 ; 2009 a)$ and compare them to the recent developments in the philosophy of science concerning explanation and causal reasoning.

\section{CONTRASTIVE EXPLANATION: WHAT IT CAN AND CANNOT DO?}

Tony Lawson presents the idea of contrastive explanation as the explanatory methodology for the social sciences. Contrastive explanation makes causal explanation possible without relying on the false idealizations of isolative economic models. According to Lawson, the "methodology" of contrastive explanation answers three crucial challenges for causal explanation in an open and internally related social world that cannot be studied experimentally: (1) how to discover and define meaningful explananda when there are no observable event regularities; (2) how to formulate meaningful causal hypotheses; and (3) how to discriminate between alternative hypotheses about causal mechanisms (2003: 81). 
The idea of contrastive explanation is certainly not alien to mainstream philosophy of science (van Fraassen 1980; Garfinkel 1981; Hesslow 1983; Woodward 1984; for a review see Ylikoski 2007), to philosophy of economics (Marchionni 2006), nor to Mäki's version of realism (Mäki and Marchionni 2011). Explanation relates contrasts because explanation is not achieved by subsuming token events under event regularities, but by exhibiting what the object of explanation depends on. This entails that the explanandum is always defined against a set of plausible alternatives and that the explanans is the factor that makes the difference between these alternative states of affairs. Yet the surface appearance of most explanations hides this contrastive structure. Most explanatory claims appear to be about a phenomenon, such as the level of unemployment, a spread in the prices of financial instruments, or the existence of excess demand in some market. Yet it does not really make sense to attempt to explain such things tout court. Akerlof's Market for lemons does not attempt to explain prices as such (even in the specific market of used cars in the US used as "a finger exercise"), but a specific contrast between the actual price difference between new and used cars and what could be expected if the price reflected only the difference in the use value of new and used cars. One of the main functions of the contrastive theory of explanations is therefore the explication of what exactly can be explained by a given explanation (Ylikoski 2007), just as Lawson claims. 
For Lawson, the role of contrastive explanation does not end with the contrastive explanandum. Contrasts do not merely explicate, but also direct explanatory inquiry. According to Lawson, a good explanandum is something that appears surprising and puzzling contrasted against the pre-theoretical expectations about the normal course of events. This, essentially, is the answer to the first challenge of social explanation: surprising contrasts pick out reasonable explananda from the clutter of internally related and emergent social life (such as a surprising price difference between brand new and only little-used cars). ${ }^{\text {ii }}$ However, there are number of problems with Lawson's version of the contrastive structure of causal inquiry.

First, it is surprising that Lawson thinks that the idea of contrastive explanation is something that sets his preferred form of economic enquiry apart from mainstream economics. It is plausible to think that mainstream economists are also in the business of accounting for differences (or at least can plausibly be interpreted as explaining differences, see Marchionni 2006). The specificity of mainstream economics does not lie here, but in the kinds of contrastive explananda they address. For example, the central heuristic assumption that the rational equilibrium is inherently understandable and that the only things requiring additional explanation are deviations from this rational benchmark, is certainly a worthwhile object of critical engagement with the mainstream. In fact, the way in which the economic explananda are related to the assumptions of 
economic theory might be a much more fruitful target of attention for a realist who is interested in critically challenging the ways of the economic discipline. The second problem is that Lawson curiously elevates an observation about the circumstances in which explanatory questions usually arise in everyday life to be a defining feature of all explanatory reasoning. For Lawson, contrast explanation - or the method of explaining critical contrasts - always addresses anomalies. It turns on accounting for surprising, noteworthy, inconsistent, disturbing, or unexpected outcomes. Surely this cannot be right. It is one of the central features of basic scientific research that it is also interested in explaining things that are usually taken for granted (Ylikoski 2007: 35-36). For example, for a theoretically oriented biologist, it is certainly more interesting to explain why grass is usually green rather than to account for those rare cases when it is not. Of course, giving up the idea that explanation is always the explanation of anomalies does not change the usefulness of contrastive ideas: the explanation of greenness is an explanation of why the grass is green rather than some other color.

The third problem is that the idea of contrastive explanandum does not get us very far. Certainly it does not deliver all the goods Lawson seems to attribute to it. The philosophical literature on causal explanation has demonstrated that a mere reference to a mechanism or to an arbitrary segment of the causal history of an event is not necessarily relevant explanatorily. Happily, the idea of contrastive explanation provides a solution: the relevant causal information picks out the 
factor that made the difference between the explanandum and its contrasts. This is the counterfactual criterion of explanatory relevance. If the explanans had been different, the explanandum would have been different as well. Lawson's own examples also clearly point to a difference-making criterion of explanatory relevance: the explanation for a surprising contrast between yields of different pieces of farmland is the factor that made the difference between the yields (Lawson 2003, 88). Unfortunately Lawson's treatment of contrastive explanation does not really address this crucial role of counterfactual reasoning in such explanations of differences and hence misses much of the epistemologically challenging issues of how and when such reasoning is warranted. As Lawson is reluctant to investigate the counterfactual nature of contrastive explanation further, he fails to acknowledge that the difference-making criterion of explanatory relevance in fact entails a (sort of) deductive constraint on explanation. In order for one to be in a position to assert that if the explanans had been different, the explanandum would have been different as well, one has to have knowledge of an invariance between the explanans and the explanandum, which enables deduction from the possible states of the explanans to possible states of the explanandum (Woodward 2003). To see this, consider again Akerlof's explanation of the price difference between new and little-used cars. We can reason that the puzzling price difference depends on the information asymmetry because the lemons-model implies that if information about the quality of the traded good were equally available to buyers and sellers (they would have equally correct expectations about the quality), the equilibrium 
market prices would only reflect actual quality differences in the traded products. This constraint does not imply that deduction is a constitutive element of explanatory relation (Ylikoski 2005), nor does it say anything about the alleged symmetry between explanation and prediction. It is certainly not necessarily related to a Humean conception of causality. It is simply a consequence of the fact that we usually represent and reason about dependencies in (propositionally structured) language.

The big question, of course, is what kind of evidence justifies counterfactual claims required for contrastive causal explanation. Mere knowledge of regularities is not enough, since the counterfactual inferences are modal in that they are about what would have happened if, not what actually has happened or even what will happen. For this, we need knowledge of causes and mechanisms.

\section{CAUSAL INFERANCE IN AN OPEN WORLD}

The second challenge of causal explanation in the open and holistic social realm, the generation of meaningful causal hypotheses, is a tougher nut to crack. Yet Lawson claims that the method of contrast explanation is also a method for causal inference. He writes "just as an event regularity produced in the experimental laboratory prima facie marks the site of a single set of causal mechanisms in play, a surprising contrast directs us to a set of causal mechanisms" (Lawson 2003: 95). 
Except that of course it doesn't. This really is the central puzzle with critical realism: since causal mechanisms and powers are not directly observable, no meaningful experiments can be carried out because of the failure of atomism in the social realm, and statistical methods do not help because there are no regularities, how are we supposed to do causal inference in the social and economic realms? Simply naming the problematic inferential step from an observed effect to an unobservable cause "retroduction" is not an answer to this question.

Lawson claims that there simply is no general solution to this problem, but hints at two principles that can lead us to the causes of observed differences: Mill's method of difference and the use of explanatory power as an evidential criterion. The method of difference is an answer to the second challenge of causal explanation, namely, how to formulate hypotheses about the causes of observed surprising contrasts. If a good comparison case for a situation in which a surprising event prompts explanatory inquiry can be found, such that it differs in only one other respect compared to the original explanandum situation, then that other differing factor is a good candidate for being the causal explanation of the contrast. In Lawson's example, the surprising contrast between yields of seemingly similar plots of land is explained by the only other observable difference, namely the proximity to water. In his response to Geoff Hodgson's criticism (Hodgson 2009), Lawson emphasizes that non-experimental social 
causal enquiry should aim for such "concomitant regularities," rather than causal sequences of events (Lawson 2009d: 203).

Given how keen Lawson is to point out the strict limits of applicability for formal modeling tools of mainstream economics, it is surprising that he does not recognize the severe limitations of his favored approach. Let us see where the problem lies. Lawson writes:

we expect a set of outcomes to be reasonably similar because of a shared (recent) causal history. Now if in such a contrast space a subset of outcomes turns out to be systematically different from the rest, we have reason both to suppose that a single (set of) causal feature(s) may be responsible, and also anticipate that we can isolate it.

(Lawson 2009c: 26)

Now, this is very optimistic. A closer look at Lawson's proposal shows that it is a variation of John Stuart Mill's difference principle (Mill [1843] 2002: 255). It also inherits most of the latter's problems. The most prominent of these is the problem of multiple principles. It is very rare to find such natural experiments in which there is only one difference between the two cases one is comparing. Precisely 
because of the "ontological nature" of economic phenomena, cases that are exactly alike except for the differences in the cause and effect variables, are very rare. It would be a remarkable stroke of luck to find two markets for used cars exactly alike except for the fact that in one the quality of the cars would be transparent to both sellers and buyers whereas in the other such information would be asymmetric. This sets a definite limit to the use of method of difference as a method of causal inference.

This fact is obscured by Lawson's loose way of talking about causes and causal mechanisms. He suggests that the controlled experiment is one way to learn about causal mechanisms. However, as many examples from medicine show, the experiment does not necessarily give us understanding of the mechanisms. It only tells us about causal dependencies - what can be brought about by a specified intervention within specific circumstances. The mechanisms underlying this causal invariance might remain unknown for a long time. It seems that Lawson has fallen victim to a common mistake: confusing the rhetorical appeal of mechanism talk with a substantial account of causation and causal inference. Nevertheless, nobody would deny that the method of difference certainly has a place in economic methodology. Comparative research strategies using rich historical case studies of economic events and institutions, possibly amended with techniques such as analytic narratives, are certainly powerful and under-utilized methods for causal inquiry in economics and Lawson is certainly right in 
advocating a more widespread use of these strategies alongside mainstream econometric modeling. But these strategies do not amount to a distinct "method of contrastive explanation" previously overlooked in economics. There is also a strong econometric tradition of conceptualizing econometric modeling as the observational equivalent of statistical analysis of controlled experiments, which aims at pinpointing "natural experiments" and then statistically controlling for the remaining differences in units studied (e.g., Heckman 2008; Angrist and Pischke 2009). Such econometric studies clearly do not aim at uncovering Humean event regularities, but at a systematic comparative study of differences with the kind of statistical data available to economists - a generalization of the method of difference. But such studies cannot be carried out without the use of mathematics.

The second epistemic principle by which contrastive explanation can get us to causes is a form of inference to the best explanation. According to Lawson, the explanation which explains the most contrasts is the one most likely to be true (2003: 95; 2009a: 410). This is the way in which contrastive explanation is supposed to help in the third challenge of picking the right mechanistic hypotheses out of a set of possible causal explanations. The intuition linking the capacity of a hypothesis to explain much by little to the probability of the explanatory hypothesis is certainly common (Lipton 2004), but its validity as an epistemic principle is in fact highly controversial. 
The general idea of inference to the best explanation can be understood in (at least) three different ways. First, a causal hypothesis which has more evidence has ... more evidence. Having multiple empirically confirmed consequences is, ceteris paribus, obviously an epistemically good thing for a causal hypothesis. But this truism does not really give us the advantage the supporters of the inference to the best explanation advocate. Second, beyond the first truism, there is the idea that the hypothesis that best unifies the phenomena, i.e. that explains as much as possible by as little as possible, is the likeliest hypothesis to be true. But there is little evidence that Lawson would be seriously committed to unification, either as an account of explanation or as an evidential virtue. Moreover, the efforts to provide a formal explication of this intuition linking unification and truth have so far proven futile (see, e.g., Schupbach 2005) Therefore, if Lawson is to claim that contrast explanation is a method for causal inference, he must be advocating the third possibility, according to which explanatory virtues are a reliable guide to truth. In other words, the explanatory merits of a hypothesis are also evidential merits. There are serious problems with this idea. First, there is the thorny problem of justifying the assumption that the loveliness of an explanation is connected with its likeliness (Lipton 2004). Second, the idea of explanatory virtue - or "power" - is quite hazy and the supporters of the inference to the best explanation have not been able to give much substance to this metaphorical notion. A closer look at the notion of explanatory power shows that this is not a one-dimensional concept and these dimensions are distinct and independent from 
evidential virtues (Ylikoski and Kuorikoski 2010). In sum, the extent to which “explanatory power" can be regarded as an epistemic principle is quite narrow: inference to the best explanation works if and only if it is interpreted as inference to the likeliest cause. But this just brings us back to the problem of causal inference. Contrastive explanation is not an independent methodology for causal inference.

Lawson's advocacy of his preferred forms of causal reasoning is indicative of how far-reaching methodological proclamations he is willing to make based on a priori philosophical argument. This distinguishes his critical realism from Mäki’s brand of cautious realism. Yet we take Lawson's optimism concerning the reliability of informal causal reasoning in the social realm to be a cautionary example of the dangers of such philosophizing. One of the sources of Lawson's unwarranted optimism concerning the ease of causal reasoning is the peculiar habit of conflating natural and conceptual dependency, which is characteristic of critical realism in general. Although the general idea that the causal relation is to be characterized in terms of necessity dates back to Hume and beyond, the specific idea that de re natural necessity of causation is transformed to conceptual necessity in the process of scientific concept formation comes from Rom Harré and Edward Madden. According to Harré and Madden (1975), successful concept formation defines theoretical entities according to their causal powers. Thus it is in the very definition of protonhood that a proton attracts negatively charged 
particles and if a particular particle fails to have this property, it simply cannot be a proton. Therefore the causal necessitation between a proton and movements of negatively charged particles is captured as a conceptual necessity in the definitions of proton and negative charge. But this does not mean that conceptual and causal necessity should be equated. The fact that they coincide in the case of the proton is a consequence of the successful accommodation of our physical vocabulary to the causal structure of the world.

When one transports this association of causation and conceptual necessity to the social realm and then adds the intuitively appealing but ill-understood idea of relational powers constituted by internal relations, one arrives at the conclusion that much of the causal relations within the social world can be deduced from the meanings of our social roles and attributes. A teacher simply could not be a teacher without being in a certain relation to other people (students) and this relation confers upon him or her the causal power to educate. In Reorienting Economics, Lawson expresses optimism about the extent of our commonsensical access to the causal structure of the social world: "if we simply transfer the successful social-theoretical practices of our everyday lives into our socialtheoretical research activities, albeit, perhaps, with the aim of pursuing these practices in more systematic, explicitly formulated, critically examined and selfreflexive ways, there is every reason to anticipate a more successful performance of our discipline." (Lawson 2003: 108) The possibility of causal knowledge 
concerning the social realm can apparently be transcendentally deduced from the indisputable fact that we can, more or less, get along with each other and act intentionally within the framework of our social institutions, and this requires valid causal knowledge about the social realm.

Lawson's optimism is remarkable given that the very idea of social science arises from the acknowledgement that the social world is not in fact transparent to its inhabitants (e.g., Guala 2010). Not only are we incapable of figuring out all the unintended consequences of our actions, not to speak of the actions of others, but much of our working knowledge of the basis of social interaction and the very drivers of our own behavior may well be seriously mistaken. A growing body of empirical evidence suggests that we are in fact not that good at pre-theoretically perceiving what makes us and our society tick (see, e.g., Uhlmann et al. 2008 and the references therein). Uncritical reliance on our commonsense understanding of the social world in general, and armchair theorizing based on semantic intuitions about the meanings of social attributes in particular, are a recipe for creating illusions of scientific understanding (Ylikoski 2009). In the case of economics, this danger is all the more pressing, since many key economic concepts seem, at first glance, to be what Mäki has called commonsensibles (Mäki 1996; see Hands in this volume and Guala in this volume). We certainly entertain all kinds of folktheories about the central entities of economics, and we have a rudimentary understanding of them which is sufficient for our individual daily lives. But 
scientific economics steps in precisely where common sense becomes insufficient and very often misleading. Our commonsensical causal understanding of economic matters is ill-equipped for dealing with large aggregates, multiple interdependent markets, and strategic interaction. Therefore transcendental deduction cannot establish the happy conclusion that the possibility of correct causal knowledge follows necessarily from the fact that we can, more or less, get along just fine with our individual economic lives.

\section{GETTING SERIOUS ABOUT MECHANISTIC REASONING}

While Lawson recognizes the comparative nature of explanatory inference, he fails to see the close connection between modeling, which he despises, and 'how possibly-reasoning', which he rightly recognizes as an important element in explanatory reasoning. We will now argue that formal modeling is really an advanced version of 'how possibly-reasoning' where the formalization on the one hand forces the modeler to be explicit about his or her assumptions, and on the other hand makes it possible to study systematically what kinds of consequences assumptions have and how these consequences change when the assumptions are changed or new elements are taken into consideration.

Although Lawson's trust in our commonsense understanding of the social realm goes too far, it is undeniable that much of the theorizing about social mechanisms 
in economics also starts from folk-psychological assumptions about individual behavior and commonsensical assumptions about the social institutions within which that behavior takes place. This is also true of the market for lemons. The "model" of the mechanism linking information asymmetry to the surprising price difference is based on commonsensical assumptions concerning the beliefs and desires of the market participants and of the general forms of their possible social interaction. What is groundbreaking about Akerlof's toy model is the reasoning of how these simple and by all accounts well-established causal platitudes can jointly lead to a surprising outcome. And as Lawson surmises (2009a: 416), the mathematical toy model in Akerlof's paper is to all intents and purposes quite superfluous for this inference task.

But not all mechanistic theorizing is as ingeniously simple as that of Akerlof's. Natural language is an unreliable tool for figuring out the consequences of our assumptions, when those assumptions imply complex interaction and have to satisfy mutual consistency conditions. Our working memory is too limited, pretheoretical concepts too vague and the sequential nature of natural language too ill-suited for reliable mechanistic reasoning. Mechanistic storytelling in natural language may often provoke a powerful sense of understanding, but this feeling may all too easily be mistaken. Lawson claims that formal modeling of mechanisms is always redundant, since in order to be (legitimately) confident about the causal interpretation of the model, we already have to possess the 
required knowledge about the modeled mechanism (see especially Lawson 2009d). But this is simply false. The mechanistic consequences of our causal assumptions are not immediately transparent. Mechanistic theorizing can provide us with hypotheses about explanatory dependencies only when we can unequivocally deduce that if some causal assumption were different, then the end result or conclusion would be different as well. This kind of reasoning cannot always be reliably carried out in natural language and certainly not just within our heads. A formal representation of the assumptions and well-defined inference rules are often necessary in making these kinds of inferences possible. In order to keep our mechanistic reasoning straight, we may have to rely on mathematical models or computer simulation. This is the main function of theoretical models and it is quite different from the asymptotical approximation of a detailed photograph-like representation of economic phenomena.

For Lawson, realism seems to entail that proper science should aim at a unique, maximally detailed, and completely true description of its target phenomena. In the philosophy of science, this stance has become known as the Perfect Model Model (Teller 2001). This model of modeling does not allow false elements a cognitive role, just as Lawson does not allow literally false isolations. Only abstraction, in the sense of temporarily omitting some features of the target phenomena from the theoretical focus, is epistemically acceptable (see Lawson 1997, chp 16). According to Lawson, theoretical isolations in Mäki's sense are a 
poor guide to economic truths since their use presupposes that the isolated powers combine "mechanistically" in economic reality. But the social realm is not atomistic and such recombination of theoretically isolated powers is not usually possible (Lawson 1997: 131-133.)

There is much truth in Lawson's concern about the difficulties in combining the theoretical insights from isolative causal models into a valid causal understanding of actual economic phenomena. Economic phenomena are more than mere aggregates of isolated causal capacities. Nevertheless, it is also noteworthy how little there is in the way of positive suggestions for better realistic alternatives in Lawson's writings. Naturally considerations of tractability create limitations as to what can be done, but it is quite absurd to give up the whole strategy of formal model building because of these limitations. After all, there are even more severe limitations for tractability and extrapolation for the kind of theoretical practice Lawson supports. A more natural reaction to these limitations is to look for more flexible modeling tools, like agent-based simulation, rather than giving up the idea of piecemeal modeling of complex phenomena. Our final point is that Lawson has failed to appreciate the way in which the very possibility of isolation itself can be seen as a heuristically useful, albeit a literally false, ontological assumption. We take our cue from William Wimsatt's (2007) discussion on reductive research heuristics. According to Wimsatt, complexity, such as that of economic phenomena, cannot be approached as a totality. It is futile to start with as rich and 
accurate a surface description of the phenomenon of interest as possible and then simply try to "understand" how it works. The point of making unrealistic, simplifying, and reductionistic models is precisely to provide a starting point, something we can meaningfully relate to the complex system being investigated, and then start learning about the system by seeing how and why the simplifying model fails. We cannot start by simply abstracting from the clutter of economic reality, because mere abstraction cannot get us to the underlying mechanisms. We are better off by first treating the constituents of social realm as if they were isolatable, and then learn about their causal interaction and interconnectedness by seeing how our atomistic, isolative models fail, and then move on to building better ones. This is the strategy of model-based science (Weisberg 2007) and any realist critic of economics should first understand its rationale. Such an understanding can be found, for example, in Uskali Mäki's philosophy of economics.

\section{TWO WAYS TO PRACTICE CRITICAL REALISM}

In this paper we have documented how the isolation of Lawson's critical realism from the developments in philosophy of science has hampered its ability to contribute to the improvement of the epistemic practices of modern economics. But as is well known, Lawson's critical realism is not the only realist game in town. In this section we will consider whether Mäki's version of realism fares better in critical engagement with the science of economics. 
Mäki (2011a) recently introduced the notion of authentic critical realism (ACR) to describe his own position. While the polemical title is new, it does not reflect any change in his philosophical position. From the beginning, Mäki has been part of the Finnish tradition of scientific realism (see Niiniluoto 1999, see also Tuomela 1985) that has emphasized the critical dimension of realism. Mäki summarizes the key ideas of ACR as follows:

ensuring a reliable epistemic access to the world is enormously difficult; cognition is the joint work by subject and object in which the subject contributes heavily; the endeavour is radically fallible; doing good science requires critical reflection of various epistemic hazards, identifying and safeguarding against sources of possible and ever-present biases and errors. This is an epistemological rather than ontological doctrine. It focuses on the complexity and proneness to hard-to-identify error of the scientific endeavour.

(Mäki 2011a, 10)

While Mäki suggests that this makes ACR rather different from Bhaskarian critical realism, both Bhaskar and Lawson could agree with the sentiment of this 
passage. Both of them accept fallibilism and neither of them would deny the complexity of the social world. In our view, the crucial differences between Bhaskarian critical realism advocated by Lawson and ACR advocated by Mäki are not to be found in any specific ontological or epistemological positions taken by Mäki and Lawson. While there are plenty of such differences - albeit some of them surprisingly small - they are not decisive. The crucial differences concern philosophical methodology and rhetorical strategy. While these differences deserve a more systematic study, in the following we will only observe two pertinent differences.

Let us start with their characterization of realism. Lawson's critical realism is an example of what Uskali Mäki and Päivi Oinas (2004) have characterized as a thick conception of realism. It consists of a package of philosophical views about causation, social ontology and scientific methodology that are added to the core ideas of realism. According to Mäki and Oinas, the critical realist bundle suffers from a double problem. On the one hand, the bundle seems to be rather weak in its realist credentials, as it does not employ some conceptual resources often associated with scientific realism. On the other hand, the bundle also appears somewhat arbitrary, as there is no obvious reason to assume that a scientific realist should accept precisely the suggested views about causation, social ontology and methodology. 
While someone might suggest that this line of criticism just reflects the fact that Mäki and Lawson have some disagreements about the details of the realist doctrine, in our view this line of argumentation springs from a deeper philosophical difference. For Lawson, realism refers to a comprehensive system of thought, while for Mäki it refers to a more limited set of philosophical theses about the mind-independent existence of the world, the concept of truth, and the attainability of truths about the world (Mäki \& Oinas 2004: 1757-1763). As a consequence, what for Lawson is a systematic theory of science, is for Mäki a more or less arbitrary collection of independent philosophical claims that should be separately argued for. Notice that Mäki does not deny that for a realism to have bite on the epistemic practices of economics, it needs to be supplemented with more specific ontological, epistemological and methodological views. The crucial thing for him is that it is a requirement of the philosophical methodology that the modular nature of the realist worldview is recognized in one's argumentation. For him, it is essential that the audience understands that there are many ways to be a realist and that everything depends on the details of the philosophical argumentation. In contrast, it seems to us that for Lawson, it is more important to get the big picture right than to attend to contingencies of his philosophical position.

This methdological difference has some important rhetorical consequences. 
Lawson's philosophical strategy makes it possible for him to present critical realism as an ontological position that has great methodological relevance and to suggest that it is a general solution for economists' philosophical problems. The drawback is that this strategy skips some crucial argumentative steps and ignores many options for alternative philosophical positions. It is not accidental that among Lawson's supporters there are very few professional philosophers. In contrast, Mäki’s approach has much more respect within this particular segment of the audience. However the nuances of Mäki's position make his task of accessing non-philosophical audiences harder. His wish to make justice to the complexity of philosophical issues (together with his philosophical personality) leads him to introduce a great deal of distinctions with the consequence that there is the danger of the relevant message getting lost in the details. Second, his persistence in focusing on the core issues of realism - that he is not providing a broader realist bundle of philosophical positions - may simply make his work seem less relevant for the social scientists.

The second crucial methodological difference concerns the application of the principle of charity in making sense of modern economics. Lawson's description of mainstream economics is quite straightforward and even stereotypical. From the point of view of his theory-driven account of the failures of neoclassical economics (Lawson 2003: Ch. 10), the employment of the principle of charity does not seem to be very important. In contrast, Mäki finds even the economic 
mainstream much less unified and is hopeful that economics might become more receptive for philosophical intervention (Mäki 2002). The same basic charity characterizes Mäki's approach to the modeling methodology applied in economics. While Lawson is eager to get rid of it on the basis of its apparent inability to produce much understanding of the economic phenomena, Mäki has emphasized the importance of understanding how this methodology actually works and what kind of understanding its users are after. In fact, most of Mäki's work on economic methodology has been concerned with precisely these issues (see Lehtinen in this volume). In his view, only after understanding what economists are attempting to do can we engage in evaluation and criticism of these practices. Notice that this methodological difference does not imply that Mäki is ultimately any less critical of the mainstream economics. It is just that the principle of charity requires withholding judgment until the ideas under consideration are properly understood.

Again, this methodological difference has some rhetorical consequences. While it is natural for Mäki to attempt to influence the mainstream economics from the inside - consider his engagement with Friedman's essay (Mäki 2009) - there is not much point for Lawson to engage in such a strategy. Given Lawson's views on the mainstream - a consequence of his philosophical methodology - it is much more prudent for him to ignore the mainstream segment of the economics audience completely. In fact, he has quite successfully championed himself as the 
philosophical critic of the neoclassical economics. While his audience - many heterodox economists and other social scientists - do not necessarily buy his complete package of critical realism, they have found him a useful ally in the advocacy of a more pluralistic economics. Mäki's strategy is a bit more difficult as he is facing two challenges that Lawson does not face. First, he has to find a right balance of criticism and defense of the mainstream in order to appeal both to mainstream and non-mainstream audiences. This is quite tricky to do. Second, in order to get a chance to influence the mainstream from the inside, he has to convince economists that he has captured the essence of their methodology. This is even more difficult to do as most economists are not used to philosophically reflect on their work and there is in fact much variation in economists' selfunderstanding of their activities.

Ultimately the fate of any kind of critical realism about economics depends on the amount and quality of improvement it brings in our understanding of economic phenomena. In this paper we have argued that Lawson's proposed alternative to the model-based strategy has some serious shortcomings. Nor does it provide many useful ideas for the improvement of economics as it is currently practiced. If one misses the key elements of model-based strategy of doing science by adopting the ideals of the so-called Perfect Model Model, it is not to be expected that this specific version of realism would provide many constructive ideas for those sciences that do employ this strategy. 
The intellectual strategy of Mäki's critical realism has been much more successful in this respect. While the details of his account are still under discussion (see the contributions to this volume), he has had an important role in providing new philosophical resources to debates about the nature of economic knowledge. However, there is also something that Mäki could learn from Lawson. While Mäki has done an admirable job in adapting standard scientific realism to economics (Mäki 2011a; 2011b), one does not get very far methodologically with only the core ideas of realism. While ideas about ontology and truth are important elements in a comprehensive account of economic knowledge, they are not the ones that would have a lasting effect on the practice of economics. They are tools for a meta-commentary about economics, not for doing economics.

To have a lasting critical impact one has to include other elements - like ideas about explanation, evidence, and epistemic standards - to one's realist package. Of course, this creates a problem for any aspiring critical realist: how to acquire credible ideas about these issues? If our diagnosis of shortcomings of Lawson's ideas is right, one should not trust one's (Aristotelian) intuitions. If one takes seriously the modular nature of the realist worldview, the idea of deriving them from one's fundamental ontology is a non-starter. And if one wishes to keep up 
the idea that there could be something seriously wrong with economics, one cannot just reconstruct them from the sayings and practices of economists.

In our view, a promising strategy for any realist with critical ambitions is that of raising the issue of compatibility of economics with the other sciences. While the old ideas of the unity of science are dead - and deserve to stay that way - there is still plenty of room for dialectical strategies that require economics - or any other discipline - to justify its methodological and theoretical idiosyncrasies. For example, if what economists think about explanation does not square with explanatory practices of physical, biological, and behavioral sciences, we have a promising leverage point. It makes possible to raise the issue of idiosyncrasy in a credible manner, but it also provides tenable positive ideas about how explanation should be conceived.

What we are suggesting is that philosophy of economics cannot be just philosophy of economic science - a credible philosophy of science should also consider how different fields and disciplines are related to each other. While the current situation in which we have philosophies of special sciences - physics, biology, economics, etc. - is preferable to earlier time when we only had highly abstract general philosophy of science, one should remember that a single-minded specialization in only one discipline might have some unintended consequences. 
Sciences as a whole provide plenty of resources for critical discourse that aims to improve epistemic practices within a single discipline. Of course, this approach is demanding, one has to get right not only economics, but also a set of other sciences. However, this is not an extra burden to a scientific realist.

\section{NOTES}

\footnotetext{
'We would like to thank Caterina Marchionni and Tuukka Kaidesoja for their critical and realistic comments.

ii This is not a novel observation. For example, Alan Garfinkel (1981) and Germund Hesslow (1983) have already provided accounts of the role of anomalous differences in causal inquiry. Later Peter Lipton (2004) has presented similar ideas.
} 


\section{REFERENCES}

Akerlof, G. (1970) “The Market for 'Lemons': Quality Uncertainty and the Market Mechanism," Quarterly Journal of Economics, 84: 488-500. Angrist J. and Pischke, J-S. (2009) Mostly Harmless Econometrics: An Empiricist's Companion, Princeton NJ: Princeton University Press. Bhaskar, R. (1975) A Realist Theory of Science, London: Verso.

— (1979) The Possibility of Naturalism: a philosophical critique of the contemporary human science, London: The Harvester Press.

Cartwright, N. (1997) “Where Do Laws of Nature Come From?” Dialectica, 51: $65-78$.

Garfinkel, A. (1981) Forms of explanation. New Haven: Yale University Press.

Guala, F. (2010) “Infallibilism and Human Kinds," Philosophy of the Social Sciences, 40: 244-264.

Hands, D. W. (1997) “Empirical Realism as Meta-Method: Tony Lawson on Neoclassical Economics," Ekonomia, 1(1997): 39-53.

Harré, R. (1970) The Principles of Scientific Thinking, London: Macmillan.

— (2004) "Iconic Modeling," in D. Rothbart (ed.) Modeling: Gateway to the Unknown: A work by Rom Harré, Amsterdam: Elsevier.

Harré, R. and Madden, E. (1975) Causal Powers, Oxford: Blackwell.

Heckman, J. (2008) “Econometric Causality,” International Statistical Review, 76 (1): $1-27$. 
Hedström, P. and Ylikoski P. (2010) "Causal Mechanisms in the Social Sciences," Annual Review of Sociology, 36: 49-67.

Hesslow, G. (1983) “Explaining Differences and Weighting Causes,” Theoria, 48: 87-111.

Hodgson, G. (2009) “On the Problem of Formalism in Economics," in E. Fullbrook (ed.) Ontology and Economics: Tony Lawson and His Critics, London and New York: Routledge,175-188.

Hoover, K. D. (2002) “Econometrics and Reality,” in U. Mäki (ed.) Fact and Fiction: Models, Realism and Social Construction, Cambridge University Press, 2002, 152-177.

Lawson, T. (1997) Economics \& Reality, London and New York: Routledge.

— (2003) Reorienting Economics, London and New York: Routledge.

— (2009a) “Applied Economics, Contrast Explanation and Asymmetric Information," Cambridge Journal of Economics 33: 405-419.

— (2009b) "Provisionally Grounded Critical Ontology - Reply to Vromen", in E, Fullbrook (ed.) Ontology and Economics: Tony Lawson and His Critics, London and New York: Routledge, 335-353.

— (2009c) 'History, Causal Explanation and 'Basic Economic Reasoning' Reply to Caldwell”, in E, Fullbrook (ed.) Ontology and Economics: Tony Lawson and His Critics, London and New York: Routledge, 20-39.

— (2009d) "On the Nature and Roles of Formalism in Economics - Reply to Hodgson," in E, Fullbrook (ed.) Ontology and Economics: Tony Lawson and His Critics, London and New York: Routledge, 189-231. 
Lipton, P. (2004) Inference to the Best Explanation, 2nd.edn, London: Routledge. Marchionni, C. (2006) "Contrastive Explanation and Unrealistic Models: The Case of the New Economic Geography," Journal of Economic Methodology 13: 425-446.

Mill, J. S. (1843/2002) A System of Logic: Ratiocinative and Inductive, Honolulu: University Press of the Pacific.

Mäki, U. (1996) "Scientific Realism and Some Peculiarities of Economics," in R.S. Cohen, R. Hilpinen and Q. Renzong (eds) Realism and Anti-Realism in the Philosophy of Science, The Netherlands: Kluwer. 427-47.

— (2002) “The Dismal Queen of the Social Sciences," in U. Mäki (ed.) Fact and Fiction in Economics, Cambridge University Press: 3-32.

— (ed) (2009) The Methodology of Positive Economics. Reflections on the Milton Friedman legacy. Cambridge: Cambridge University Press.

- (2011a) "Scientific Realism as a Challenge to Economics (and vice versa)," Journal of Economic Methodology, 18: 1-12.

— (2011b) "Realism and Antirealism about Economics,” in U. Mäki (ed.) Handbook of the Philosophy of Economics, Amsterdam: Elsevier NorthHolland.

Mäki, U. and Marchionni, C. (2011) "Economics as Usual. Geographical Economics Shaped by Disciplinary Constraints," in J. Davis and D.W. Hands (eds) Elgar Companion to Recent Economic Methodology, Cheltenham: Edward Elgar. 
Mäki, U. and Oinas, P. (2004) "The Narrow Notion of Realism in Human Geography," Environment \& Planning A, 36: 1755-76.

Niiniluoto, I. (1999) Critical Scientific Realism, Oxford: Clarendon Press.

Schupbach, J. N. (2005) "On a Bayesian Analysis of the Virtue of Unification," Philosophy of Science, 72: 594-607.

Teller, P. (2001) “Twilight of the Perfect Model Model,” Erkenntnis 55: 393-415.

Tuomela, R. (1985) Science, Action, and Reality; Dordrecht: D. Reidel.

Uhlmann, E., Pizarro D. and Bloom P. (2008) "Varieties of Social Cognition," Journal for the Theory of Social Behaviour, 38: 293-322.

Van Fraassen, B.C. (1980) The Scientific Image, Oxford: Clarendon Press.

Vromen, J. (2009) “Conjectural Revisionary Ontology,” in E. Fullbrook (ed.) Ontology and Economics: Tony Lawson and His Critics, London and New York: Routledge, 325-334.

Weisberg, M. (2007) "Who is a Modeler?" The British Journal for the Philosophy of Science, 58: 207-233.

Wimsatt, W. (2007) Re-engineering Philosophy for Limited Beings: Piecewise Approximations to Reality, Cambridge MA: Harvard University Press.

Woodward, J. (1984) “A Theory of Singular Causal Explanation,” Erkenntnis, 21: 231-236.

Woodward, J. (2003) Making Things Happen. A Theory of Causal Explanation, Oxford: Oxford University Press.

Ylikoski, P. (2005) “The Third Dogma Revisited," Foundations of Science, 10: $395-419$. 
— (2007) "The Idea of Contrastive Explanandum," in J. Persson and P. Ylikoski

(eds) Rethinking Explanation, Dordrecht: Springer, 27-42.

— (2009) “The Illusion of Depth of Understanding in Science," in H. De Regt, S.

Leonelli and K. Eigner (eds) Scientific Understanding: Philosophical

Perspectives, Pittsburgh: Pittsburgh University Press, 100-119.

Ylikoski, P. \& Kuorikoski J. (2010) "Dissecting Explanatory Power,"

Philosophical Studies, 148: 201-219. 